\title{
ACM Europe
}

\section{Increasing ACM's relevance and influence as a membership organization in the global computing community has been a top priority from the outset of my presidency.}

For it is only by making concerted efforts to share ACM's vast array of valued resources and services on a global scale, and by discovering the work and welcoming the talent from all corners of the computing arena, that ACM can truly call itself the world's leading computing society.

To this end, ACM has made impressive strides over the last year. Major internationalization initiatives have resulted in multiyear plans for raising the Association's visibility and promoting membership in the major technology hubs of Europe, India, and China. A growing number of ACM's Special Interest Groups (SIGs) are hosting or planning their flagship conferences throughout Asia, Europe, and Latin America. And ACM's Executive Committee, Council, as well as its many Boards and Committees stand solidly behind this cause, fully recognizing what it means - and what it takes - for ACM to be an international society.

As the Association's first non-North American President, and a European, I am especially pleased to announce ACM Europe - a new effort within ACM to recognize and support European members and ACM activities in Europe. Dedicated ACM volunteers and executive staff have been working with industry and academic leaders in Europe to determine ways to better serve ACM's current European members and to draw more into the fold. By strengthening its ties in the region, ACM will be better positioned to appreciate the key issues and challenges within Europe's academic, research, and professional computing communities and to respond effectively.

To celebrate the introduction of ACM Europe, the Association will host a special event in Paris on October 8 in conjunction with the 2009 European Computer Science Summit, sponsored by Informatics Europe (http://www. informatics-europe.org/ECSS09/). The reception will honor the achievements of European computer scientists and recognize European winners of ACM's A.M. Turing Award, as well as other ACM award winners, and ACM Fellows. The event will also serve to share the work and activities planned by ACM Europe.

\section{ACM Europe Council}

ACM Europe is spearheaded by the ACM Europe Council-a group of 15 noted European computer scientists from academia and industry who came together last October pledging to help build an ACM presence that would focus on bringing high-quality technical activities, conferences, and services to ACM members and computing professionals throughout the continent. Chairing the ACM Europe Council is Fabrizio Gagliardi, director of external research programs for Microsoft Research Europe. (Council members are listed here.)

The roots of ACM's European community are as old and run as deep as the Association itself, having been in existence over 50 years. Today's ACM Euro-

\section{ACM Europe Council}

\section{CHAIR:}

Fabrizio Gagliardi, Switzerland

\section{MEMBERS:}

Andrew McGettrick, Scotland

Marc Shapiro, France

Thomas Hofmann, Switzerland

Gerhard Schimpf, Germany

Alexander Wolf, U.K.

Gabriele Kotsis, Austria

Jan van Leeuwen, The Netherlands

Avi Mendelson, Israel

Michel Beaudouin-Lafon, France

Burkhard Neidecker-Lutz, Germany

Bertrand Meyer, Switzerland

Paul Spirakis, Greece

Wendy Hall, U.K. (and ACM President)

Mateo Valero, Spain pean contingent includes over 15,000 members, more than 100 chapters, and an ever-growing number of ACMsponsored conferences and symposia. The primary goal of ACM Europe is to serve ACM's European members by improving the exchange of ideas, and by raising awareness about ACM with the public and with European decision makers in order to play an active role in critical technical, educational, and social issues related to computing.

The ACM Europe Council has established three subcommittees to launch its initial work in serving its constituency. One subcommittee will review the current landscape of European chapters and help develop strategies for increasing the number of chapters, particularly student chapters. A second group will focus on generating interest in, and nominations for, the many ACM professional awards and distinguished member grades. This group will also work to suggest names for key ACM volunteer positions to add a stronger European presence and perspective to the Association's future plans. The third group will work toward engaging ACM's SIGs to "think Europe" when planning conferences and major events.

ACM Europe is one of many international initiatives currently at the top of ACM's agenda. Planning is already under way for the newly formed ACM India Council to host a launch event in early 2010 and we will be announcing details of our plans for the development of ACM China next year. ACM SIGs continue to hold record numbers of conferences outside North America.

When I agreed to accept the invitation to run for president of ACM in early 2008, I noted in my election statement that I truly believed ACM's future success depends on its ability to increase its diversity and support of academic and research communities around the world. Given the progress made so far through the efforts and ongoing interest of so many devoted volunteers and ACM leaders to this cause, I am heartened to say that we are well on the way to successfully achieving our aims. $\quad$ C

Professor Dame Wendy Hall (wh@ecs.soton.ac.uk) is president of ACM and a professor of computer science at the University of Southampton, U.K.

(C) 2009 ACM 0001-0782/09/1000 $\$ 10.00$ 